\title{
PENGARUH PERLAKUAN PANAS PADA SIFAT MEKANIK DAN DAYA HANTAR LISTRIK PADUAN AIZrCe SETELAH HOT ROLLING DAN DILANJUTKAN DENGAN COLD ROLLING
}

\section{EFFECT OF HEAT TREATMENT ON MECHANICAL PROPERTIES AND ELECTRICAL CONDUCTIVITY OF AIZrCe ALLOY AFTER PROCESSED BY HOT ROLLING AND FOLLOWED BY COLD ROLLING}

\author{
Suryadi a, Mirza Wibisono a, Amilatin Rohmah a, Hernadi ${ }^{\text {b, Kirman }}{ }^{\text {b }}$, Iwan Setyadi a \\ a Pusat Teknologi Material - BPPT, \\ Gedung Teknologi 224 Kawasan Puspiptek Serpong-Tangerang Selatan \\ b B2TKS - BPPT Gedung B2TKS, Kawasan Puspiptek Serpong-Tangerang Selatan \\ e-mail : suryadi.chun@gmail.com, mirza_w@yahoo.com ,amil.atin13@gmail.com, \\ hernadi@bppt,kirmanmt@gmail.com, i1setyadi2810@gmail.com
}

\begin{abstract}
Abstrak
Percobaan hot rolling pada temperatur $450{ }^{\circ} \mathrm{C}$ yang dilanjutkan dengan cold rolling (temperatur kamar) terhadap dua jenis sampel paduan AIZrCe dengan komposisi serium (Ce) $0,2 \%$ dan $0,3 \%$ serta komposisi $\mathrm{Zr} 0,13 \%$ yang sebelumnya diproduksi melalui proses gravity casting telah dilakukan pada kajian ini. Setelah proses rolling dilanjutkan dengan perlakuan panas terhadap sampel dengan temperatur pemanasan 150 , 230 dan $350{ }^{\circ} \mathrm{C}$ yang ditahan selama 2 dan 4 jam. Untuk mengetahui perubahan sifat mekanis sampel telah dilakukan uji kekerasan dengan metode Vickers dan uji tarik. Untuk mengetahui perubahan struktur mikro dilakukan proses metalografi sampel yang dilanjutkan dengan pengamatan menggunakan mikroskop optik (OM) dan scanning electron microscopy (SEM). Selanjutnya untuk mengetahui sifat konduktivitas listrik bahan dilakukan pengukuran koduktivitas listrik menggunakan metode Eddy current. Proses cold rolling setelah hot rolling meningkatkan nilai kekerasan dan kekuatan tarik sampel. Selanjutnya pada perlakuan panas sampai temperatur $230^{\circ} \mathrm{C}$ terjadi peningkatan nilai kekerasan dan kekuatan tarik untuk lama pemanasan 2 jam, sedangkan pada lama pemanasan 4 jam terjadi sedikit penurunan, namun nilai konduktivitas listrik cenderung meningkat. Pemanasan pada temperatur yang lebih tinggi dengan waktu tahan yang lebih lama signifikan menurunkan nilai kekerasan dan kekuatan, namun signifikan menaikan nilai konduktifitas listrik. Untuk kadar Ce 0,2 dan 0,3\%, semakin tinggi kadar Ce signifikan meningkatkan kekuatan namun kunduktifitas listrik lebih rendah.
\end{abstract}

Kata kunci : paduan AlZrCe, hot rolling, cold rolling, heat treatment, kekuatan tarik, koduktivitas listrik.

\begin{abstract}
Hot rolling experiments at $450{ }^{\circ} \mathrm{C}$ followed by cold rolling of two AlzrCe alloy samples with $0.2 \%$ and $0.3 \%$ cerium $(\mathrm{Ce}$ ) composition and $0.13 \% \mathrm{Zr}$ composition previously produced by gravity casting process was carried out. After the rolling processes, the samples processed heat treatment with heating temperatures of 150, 230 and $350{ }^{\circ} \mathrm{C}$ hold for 2 and 4 hours.
\end{abstract}


The change of mechanical properties the samples observed by hardness test with Vickers method and tensile test. The change of micro structure of the samples observed by optical microscopy and scanning electron microscopy (SEM) after prepared by metallography. Furthermore, the electrical conductivity of samples measured by the Eddy current method. The hardness and tensile strength of the cold rolling samples were increased after hot rolling increases. Furthermore, the hardness and tensile strength of samples were increases after heat treatment at a temperature up to $230^{\circ} \mathrm{C}$ for 2 hours, but on heating the same temprature for 4 hours there were a slight decreased, but tends to be increased the electrical conductivity. Heating at higher temperatures with longer lasting times significantly decreases the hardness and strength, but significantly raises the electrical conductivity. Higher cerium $(\mathrm{Ce})$ content was significantly increased strength but lower electrical conductivity.

Key Words : AIZrC alloy, hot rolling, cerium, tensile strength, electrical conductivity

Diterima (received) : 8 Desember 2017, Direvisi (revised) : 19 Februari 2018, Disetujui (accepted) : 29 Maret 2018

\section{PENDAHULUAN}

Berbagai upaya dilakukan untuk mendapatkan sifat fisik dan mekanik dari suatu logam untuk aplikasi tertentu. Perbaikan sifat fisik dan mekanik tersebut dapat berupa penambahan unsur paduan pada saat pembuatan bahan dasar dari produk tersebut, dapat berupa tahapan proses pembentukan yang dilalui sampai terjadinya produk tersebut seperti proses rolling, forging, machining dan sebagainya. Selanjutnya setelah jadi dalam bentuk produk perbaikan sifat mekanik masih dapat dilakukan dengan perlakuan panas.

Pada sistem transmisi listrik tegangan tinggi digunkan konduktor dari logam aluminium murni ataupun aluminium paduan. Meskipun memiliki daya hantar hanya sekitar $60 \%$ dari tembaga, namun dengan berat jenis $\left(2,7 \quad \mathrm{~kg} / \mathrm{dm}^{3}\right)$ yang jauh dibawah tembaga $\left(8,7 \mathrm{~kg} / \mathrm{dm}^{3}\right)$ maka aluminium sangat cocok untuk listrik tegangan tinggi ${ }^{1-3)}$. Salah satu konduktor aluminium yang dibutuhkan adalah konduktor tahan panas yang harus tahan pada temperatur $150{ }^{\circ} \mathrm{C}$ selama 1 jam 1-3), dengan penambahan unsur zirconium ( $\mathrm{Zr})^{1,4-9)}$. Penambahan unsur paduan dapat menurunkan sifat fisik atau mekanik tertentu. Penambahan $\mathrm{Ce}$ pada paduan AIZr dapat meningkatkan daya hantar listrik $4,5,8)$.

Secara umum proses produksi diawali dengan proses peleburan pemaduan dan dilanjutkan dengan penuangan secara kontinu dan proses pengerolan panas (hot rolling) menghasilkan bentuk batang kawat serta dilanjutkan dengan proses wire drawing sampai menjadi kawat dan dilanjutkan dengan perlakuan panas ${ }^{10-11)}$.

Pada penelitian ini akan dilakukan percobaan hot rolling pada temperatur 450 $450{ }^{\circ} \mathrm{C}$ dan dilanjutkan dengan cold rolling (tempertur kamar) dengan reduksi tertentu, lalu dilanjutkan dengan perlakuan panas pada berbagai temperatur pemanasan dan lama pemanasan. Selanjutnya dilakukan pengujian kekuatan tarik, kekerasan, struktur mikro dan daya hantar listrik pada setiap tahapan proses untuk mengetahui karakteristik paduan $\mathrm{AIZrCe}$ pada setiap tahapan proses (as cast, hot rolling, cold rolling, dan perlakuan panas)

\section{BAHAN DAN METODE}

Pada Gambar 1 dapat dilihat diagram alir penelitian yang menggambarkan metodologi penelitian. Sampel paduan aluminium $\mathrm{AIZrCe}$ berasal dari batang dengan dua komposisi paduan cerium $(0,2 \%$ dan $0,3 \%$ ) seperti dapat dilihat pada Tabel 1. Sampel paduan dihasilkan dari proses gravity dalam bentuk slab dengan tebal 20 $\mathrm{mm}$. Selanjutnya sampel dari tebal $20 \mathrm{~mm}$ diproses hot rolling sampai ketebalan $10 \mathrm{~mm}$ (reduksi $50 \%$ ) pada temperatur $450{ }^{\circ} \mathrm{C}$ dan dilanjutkan dengan proses cold rolling sampai ketebalan $5 \mathrm{~mm}$ (reduksi 50\%) dan 3 $\mathrm{mm}$ (reduksi $70 \%$ ).

Selanjutnya sampel diproses perlakuan panas dengan berbagai temperatur pemanasan yaitu 150,230 dan $350{ }^{\circ} \mathrm{C}$ dengan lama pemanasan 2 dan 4 jam. Sampel diproses rolling menggunakan mini 
rolling mill (Gambar 2), proses perlakuan panas menggunakan muffle furnace.

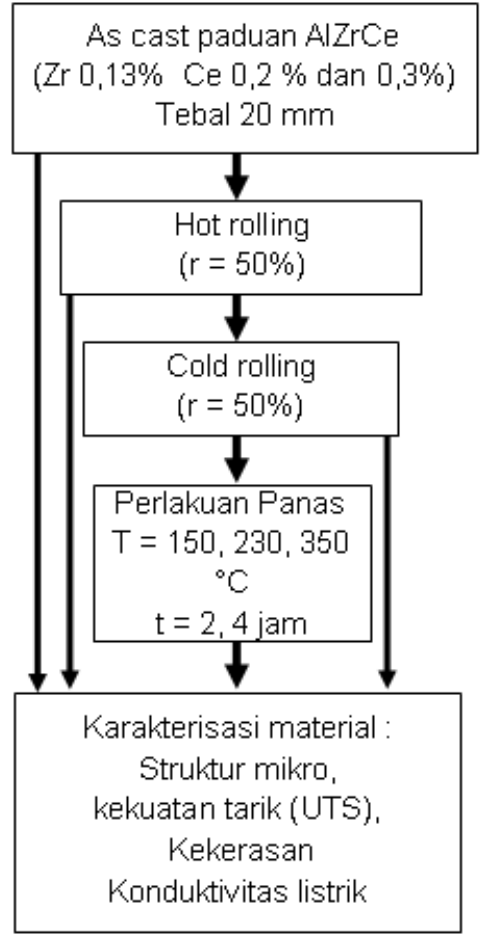

Gambar 1.

Diagram Alir Penelitian

Tabel 1.

Komposisi kimia paduan AlZrCe (\%wt.)

\begin{tabular}{cccccccc} 
Paduan & $\mathrm{Al}^{* *}$ & $\mathrm{Si}$ & $\mathrm{Fe}$ & $\mathrm{Ni}$ & $\mathrm{Zn}$ & $\mathrm{Zr}$ & $\mathrm{Ce}^{*}$ \\
\hline $\begin{array}{c}\text { AlZrCe } \\
0,2\end{array}$ & 99.41 & 0.07 & 0.15 & 0.02 & 0.02 & 0.13 & 0.20 \\
$\begin{array}{c}\text { AlZrCe } \\
0,3\end{array}$ & 99.27 & 0.09 & 0.17 & 0.02 & 0.01 & 0.14 & 0.31 \\
\hline
\end{tabular}

** balance, *diukur dengan metode ICP

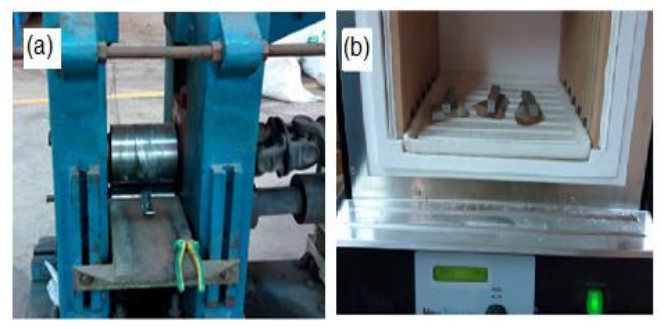

Gambar 2.

(a) Mini rolling mill dengan Diameter Rol 140 mm untuk Proses Hot dan Cold Rolling, dan

(b) Muffle Furnace untuk Proses Reheating dan Perlakuan Panas.

Untuk melihat perubahan sifat mekanis paduan dilakukan pengujian tarik dengan sampel mengacu pada standar ASTM E-8 dan pengujian kekerasan Vickers. Perubahan struktur mikro sampel diamati dengan menggunkan mikroskop optik dengan terlebih dahulu sampel dipotong dengan permukaan yang akan diamati dilakukan proses pengerindaan, pemolesan dan pengetsaan dengan larutan etsa keller reagen ${ }^{11)}$. Daya hantar listrik sampel diukur dengan menggunkan eddy current method dengan nilai pengukuran dibandingkan dengan tembaga murni (\%IACS) ${ }^{4-8}$.

\section{HASIL DAN PEMBAHASAN}

\section{Pengamatan Struktur Mikro}

Pada Gambar 3 dapat dilihat foto struktur mikro sampel paduan AlZrCe dengan komposisi $\mathrm{Ce}$ 0,2\% dan 0,3\% setelah diproses hot rolling (Gambar 3(a)(b)), dilanjutkan dengan proses cold rolling (Gambar 3(c)-(d)) dan dilanjutkan dengan proses perlakuan panas dengan temperatur pemanasan $230{ }^{\circ} \mathrm{C}$ selama 2 jam. Setelah hot rolling terlihat struktur mikro dengan ukuran butir yang relatif seragam dengan bentuk sedikit membulat. Sedangkan setelah cold rolling terlihat struktur mikro memanjang (pipih) sesuai dengan arah pengerolan. Hal ini sesuai dengan prinsip pengerolan dingin dimana butir akan terdeformasi memanjang searah pengerolan. Pemanasan setelah cold rolling menunjukkan struktur mikro cenderung berbentuk equiaxe (bulat) namun terlihat ukuran butir masih relatif seragam. Terlihat untuk paduan dengan komposisi $\mathrm{Ce}$ $0,3 \%$ memiliki ukuran butir yang lebih kecil dibanding komposisi $0,2 \%$. Hal ini sesuai dengan peran $\mathrm{Ce}$ dalam paduan juga sebagai grain refiner ${ }^{3,4,8)}$.

\section{Sifat Mekanik}

Pada Gambar 4 dapat dilihat garifik yang menunjukkan hasil uji kekerasan dan hasil uji tarik sampel paduan AIZrCe setelah proses hot rolling dan cold rolling. Pada Gambar 3(a) terlihat nilai kekerasan meningkat signifikan dari $29 \mathrm{HV}$ menjadi 45 $\mathrm{HV}$ dan $50 \mathrm{HV}$ sebelum diproses hot rolling (as cast), setelah hot rolling dan cold rolling untuk komposisi $\mathrm{Ce}$ 0,2\%. Sementara untuk proses yang sama dengan komposisi $\mathrm{Ce}$ $0,3 \%$ nilai kekerasan naik dari $32 \mathrm{HV}$ ke 46 HV dan 51. Terlihat nilai kekersan untuk paduan dengan $\mathrm{Ce} \quad 0,3 \%$ lebih tinggi dibandingkan dengan paduan dengan $\mathrm{Ce}$ $0,2 \%$. Demikian juga dengan nilai kekuatan tarik (Gambar 4(b)) kekuatan tarik paduan dengan $\mathrm{Ce}$ 0,2\% meningkat dari $164 \mathrm{MPa}$ setelah hot rolling menjadi $206 \mathrm{MPa}$ setelah cold rolling. Untuk $\mathrm{Ce}$ 0,3\% kekuatan tarik naik dari $171 \mathrm{MPa}$ menjadi $214 \mathrm{MPa}$. Hal ini 
sesuai dengan penelitian sebelumnya ${ }^{7,8)}$ pengaruh penambahan paduan $\mathrm{Ce}$.

Pada Gambar 5 dapat dilihat nilai kekerasan dan kekuatan tarik sampel setelah perlakuan panas dengan temperatur pemanasan $150^{\circ} \mathrm{C}, 230^{\circ} \mathrm{C}$, dan $350^{\circ} \mathrm{C}$ selama 2 dan 4 jam. Untuk kedua jenis paduan terlihat nilai kekerasan cenderung meningkat (52 dan $54 \quad \mathrm{HV}$ ) setelah pemanasan $150^{\circ} \mathrm{C}$ selama 2 jam ataupun 4 jam dan sedikit turun pada temperatur pemanasan $230^{\circ} \mathrm{C}(51 \mathrm{HV}$ dan $53 \mathrm{HV})$ dan turun signifikan pada temperatur pemanasan $350^{\circ} \mathrm{C}$ (39 dan $\left.40 \mathrm{HV}\right)$.

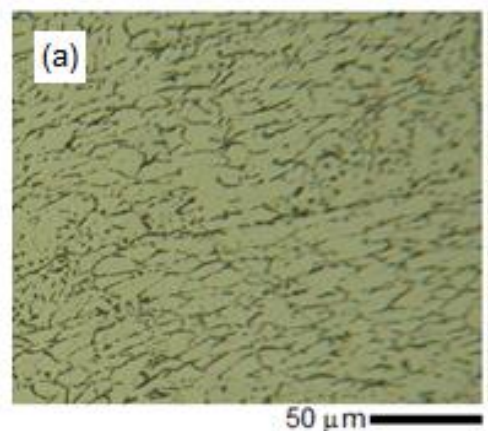

$50 \mu \mathrm{m}$

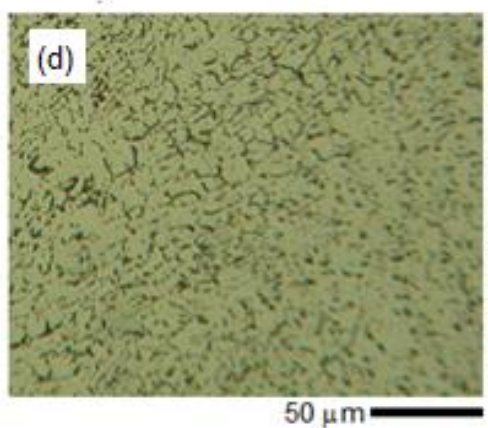

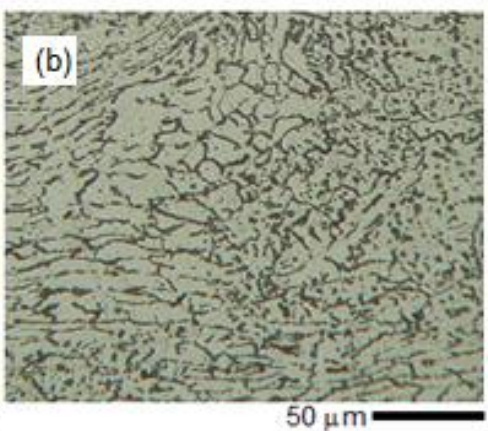
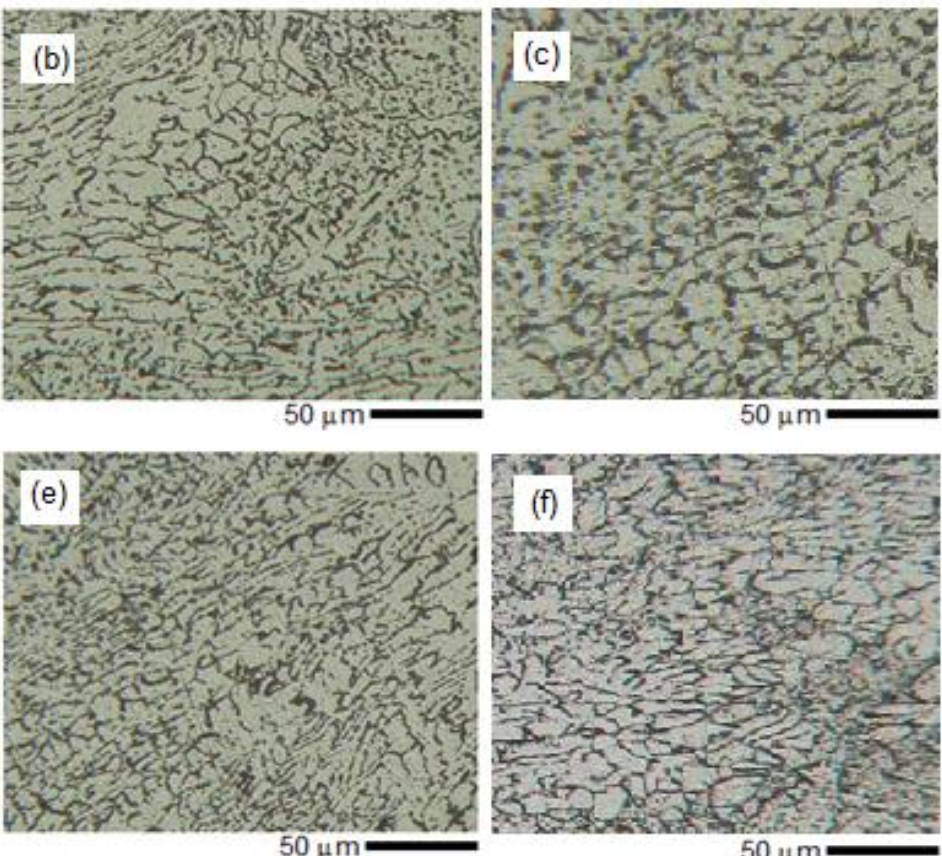

50

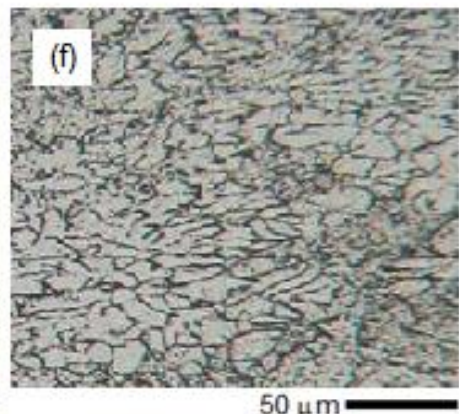

$50 \mu \mathrm{m}$
Gambar 3.

Foto Struktur Mikro Sampel Paduan AlZrce dengan (a) Kandungan 0,2\% setelah Hot

Rolling ( $r=50 \%)$, (b) Setelah Cold Rolling ( $r=50 \%)$, dan (c) Setelah Pemanasan pada Temperatur $230^{\circ} \mathrm{C}$, (d) Kandungan Ce $0,3 \%$ setelah Hot Rolling ( $\left.r=50 \%\right)$, (b) Setelah Cold Rolling ( $\mathrm{r}=50 \%)$, dan (c) Setelah Pemanasan pada Temperatur $230^{\circ} \mathrm{C}$.

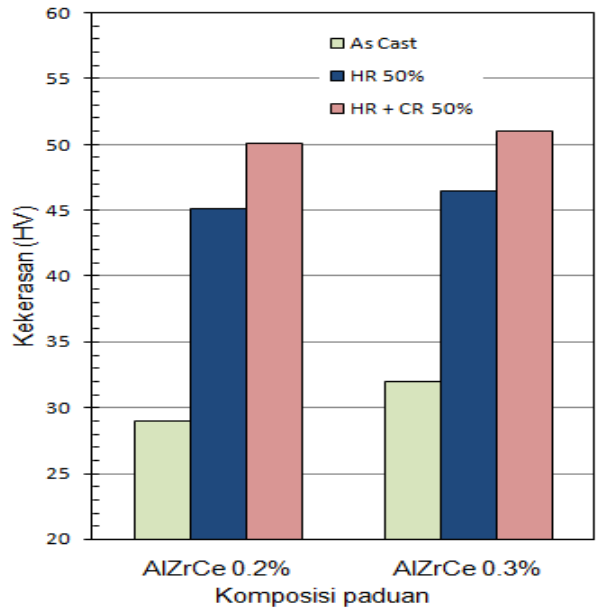

(a)

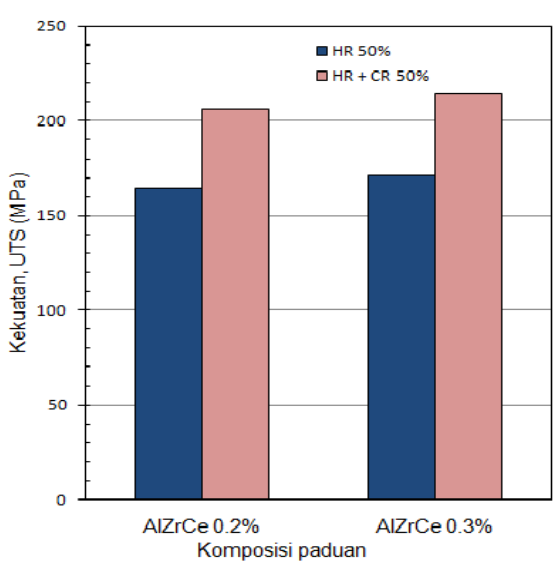

(b)

Gambar 4.

(a) Nilai Kekerasan dan (b) kekuatan tarik (UTS) Sampel Paduan AIZrCe dengan Komposisi Ce $0, \%$ dan $0,3 \%$ sebelum Hot Roling (as cast), setelah Hot Rolling (reduksi 50\%) dan Dilanjutkan dengan Cold Rolling (reduksi 50\%) 


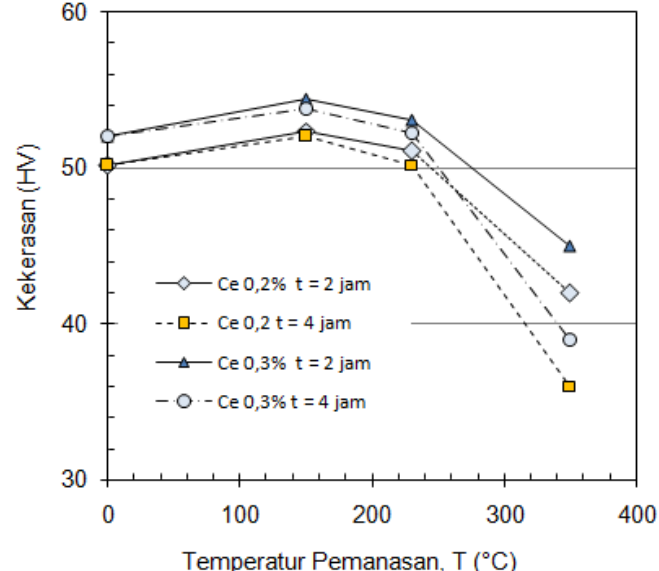

(a)

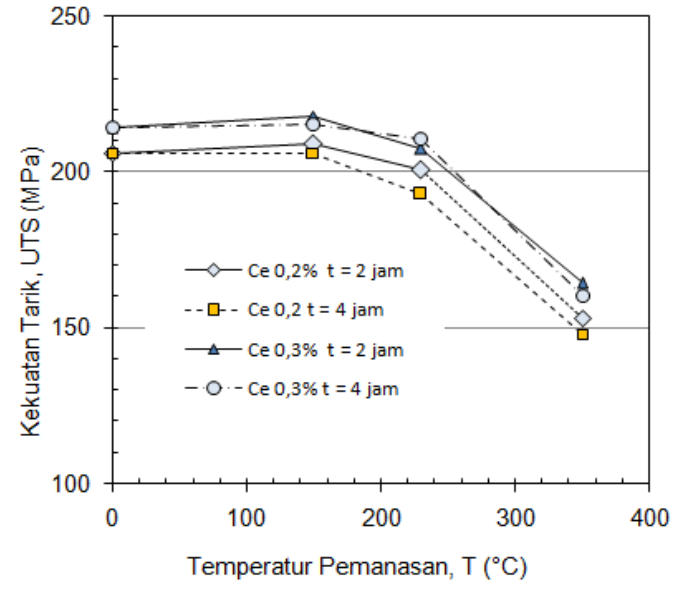

(b)

Gambar 5

(a) Nilai Kekerasan dan (b) Kekuatan Tarik (UTS) Sampel Paduan AIZrCe dengan Komposisi Ce 0,\% dan 0,3\% setelah Pemanasan pada Temperatur $150^{\circ} \mathrm{C}, 230^{\circ} \mathrm{C}$ dan $350^{\circ} \mathrm{C}$ selama 2 dan 4 jam.

Pada pemanasan yang lebih lama nilai kekerasan cenderung turun. Sementara itu kekuatan tarik menunjukan perubahan yang cenderung sama. Kekuatan tarik setelah pemanasan $150^{\circ} \mathrm{C}$ meningkat menjadi 209 dan $207 \mathrm{MPa}$ pada pemanasan 2 jam dan 4 jam, namun pada temperatur $230^{\circ} \mathrm{C}$ turun menjadi 201 dan $193 \mathrm{MPa}$, namun masih jauh di atas aluminium konduktor yaitu 160 $\mathrm{MPa}[10]$ persyaratan yaitu $170 \mathrm{MPa}$. Pemanasan pada temperatur yang lebih tinggi secara signifikan menurunkan nilai kekerasan dan kekuatan.

\section{Konduktivitas Listrik}

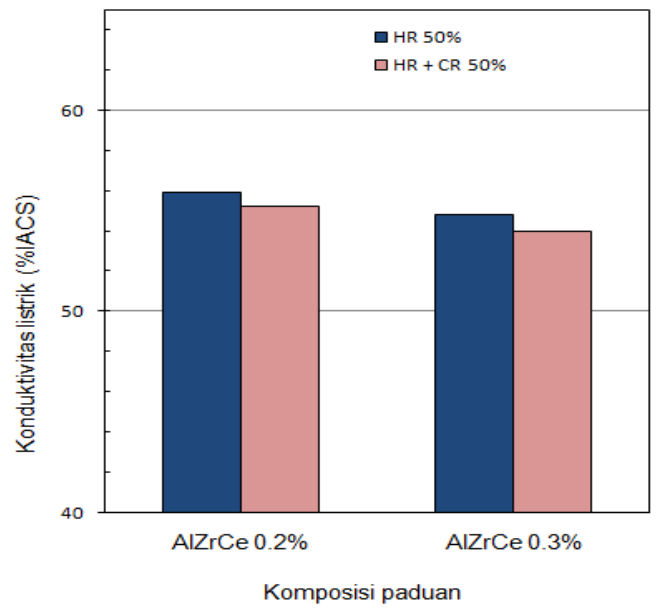

Gambar 6.

Konduktivitas Listrik Sampel Paduan AlZrCe dengan Komposisi Ce 0,2\% dan 0,3\% setelah Hot Rolling (Reduksi 50\%) dan dilanjutkan dengan Cold Rolling (Reduksi 50\%)
Pada Gambar 6 dapat dilihat nilai konduktivitas listrik paduan $\mathrm{AlZrCe}$ setelah hot rolling dan cold rolling. Terlihat konduktivitas listrik paduan cenderung turun setelah proses cold rolling yaitu $55,9 \%$ ke $55,2 \%$ untuk komposisi $\mathrm{Ce}$ 0,2\% dan dari 54,9 ke 53,9 untuk Ce 0,3\%.

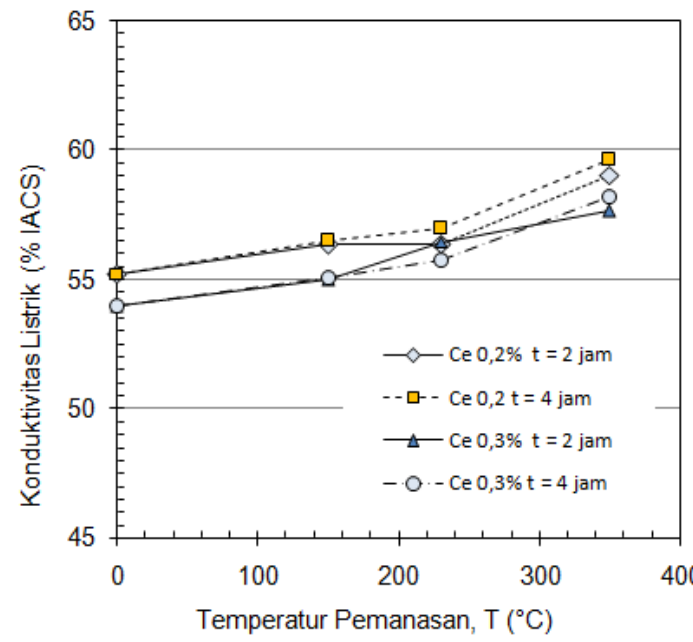

Gambar 7.

Konduktivitas Listrik Sampel Paduan AlZrCe dengan Komposisi Ce 0,2\% dan 0,3\% Hasil Hot Rolling dilanjutkan dengan Cold Rolling setelah Perlakuan Panas dengan Berbagai

Temperatur dan Lama Pemanasan.

Pada Gambar 7 dapat dillihat perubahan nilai konduktivitas listrik setelah pemanasan pada berbagai temperatur. Terlihat daya hantar listrik cendering meningkat dengan 
semakin tingginya temperatur pemanasan dan semakin lama pemanasan. Hal ini menunjukan pemanasan yang terlalu lama menyebabkan terjadinya pelunakan karena anealing namun struktur yang terbentuk lebih homogen.

\section{SIMPULAN}

Perlakuan panas paduan $\mathrm{AlZrCe}$ dengan komposisi $\mathrm{Ce}$ 0,2\% maningkatkan sifat mekanik sampai temperatur $230^{\circ} \mathrm{C}$ meningkat sifat mekanik yang menandakan terjadi artificial aging, sedangkan pemanasan pada temperatur yang lebih tinggi dengan pemanasan yang lebih lama terjadi penurunan nilai kekerasan dan kekuatan tarik yang menunjukkan terjadinya pelunakan (anil) pada paduan setelah dirol dingin. Konduktivitas listrik paduan meningkat dengan temperatur pemanasan yang lebih tinggi dan waktu yang lebih lama. Kondiuktivitas listrik dari sekitar 55\% meningkat sampai $59 \%$ IACS setelah pemanasan $350{ }^{\circ} \mathrm{C}$ selama 4 jam. Terlihat konduktivitas listrik paduan dengan $\mathrm{Ce} 0,2 \%$ lebih tinggi dibanding $\mathrm{Ce} 0,3 \%$ dan sebaliknya nilai kekerasan dan kekuatan tarik paduan dengan $\mathrm{Ce} 0,2 \%$ lebih rendah dari $\mathrm{Ce} 0,3 \%$.

\section{UCAPAN TERIMA KASIH}

Ucapan terima kasih disampaikan kepada Kementrian Riset Teknologi dan Pendidikan Tinggi atas pembiayaan penelitian melalui Progran Inssentif Riset Nasional (INSINas) tahun 2016 dan tahun 2017.

\section{DAFTAR PUSTAKA}

1) Aluminium Electrical Conductor Handbook, 3th. ed. The Aluminium Association (1989)

2) William D. Callister, Fundamentals of Materials Science and Engineering, New York, John Wiley \& Sons, Inc., 2012,

3) Serope Kalpakjian, Manufacturing Engineering \& Techology, USA, Prentice Hall Inc., 2014

4) Li Pengfei, Wu Zhigang, Wang Yunli, Gao Xizhu, Wang Zaiyun,Li Zhiqiang, Effect Of Cerium On Mechanical Performance And Electrical Conductivity of Aluminum Rod for Electrical Purpose, Journal of Rare Earth, Vol.24, Spec. Issue, (Dec. 2006), p. 355.
5) Kirman, M. Anne Zulfia, Sutopo, Bambang Suharno, Investigation On Mechanical Properties of AlZrCe- $\mathrm{Al}_{2} \mathrm{O}_{3}$ Nanocomposites Fabricated by Stir Casting, IOP Conference Series: Material Science and Engineering 58 (2014) 012009

6) Kirman, M; Maulana, Panji; Zulfia, Anne, Characteristics of $\mathrm{AlZrCe}-\mathrm{Al}_{2} \mathrm{O}_{3}$ Nanocomposites Produced by Stir Casting Method as an Alternative Material for Electrical Applications, Advanced Science Letters, Volume 20, Numbers 10-12, October 2014, pp. 2271-2274(4) 5 www.Ime.com, LME September 2015.

7) Pan, F., Edmond, D.V., Zhou S., and Ding, P.,Effect of Rare Earth Metals on Electrical Conductivity and Mechanical Properties of Commercial Purity Aluminum, Material Science and Technology , Vol.10, (1994)

8) Iwan Setyadi, Suryadi, Kirman, Mirza Wibisono, Pengaruh Proses Hot Rolling dan Komposisi Cerium pada Sifat Mekanik dan Daya Hantar Listrik Paduan AlZrCe, Jurnal: Majalah Pengkajian Industri volume 10 No. 3 (2016)

9) Suhartono, Agus H., Analisa Kehandalan Mekanik Kabel Saluran Udara Tegangan Ekstra Tinggi, Jurnal Sains dan Teknologi, Vol. 6 No 2. (Agustus 2004) p. 23-31.

10) Karabay S., Ertürk A.T., Zeren M., Yamanoğlu R., Karakulak E., Failure analysis of wire-breaks in aluminum conductor production and investigation of early failure reasons for transmission lines, Engineering Failure Analysis 83 (2018) 47-56

11) Kalomboa R.B., Martíneza J.M.G., Ferreiraa J.L.A., da Silvaa C.R.M., Araújoa J.A., Comparative fatigue resistance of overhead conductors made of aluminium and aluminium alloy: tests and analysis, Procedia Engineering 133 6th Fatigue Design Conference ( 2015 ) $223-232$

12) Sidney H. Avner, "Introduction to Physical Metalurgy", MC. Graw-Hill Inc., 2004. 